\title{
Pedagogies alternatives i pràctiques d'aula en educació infantil: la veu dels docents
}

\author{
Laura Benages-Garcia ${ }^{1}$ (D) Aida Sanahuja-Ribés ${ }^{2}$
}

Article de recerca. Rebut: 08/09/2020. Acceptat: 19/11/2020. Publicat en avançada: 28/12/2020. Publicat: 04/01/2021.

\begin{abstract}
Resum
INTRODUCCIÓ. El present article té com a propòsit indagar sobre les pràctiques de trenta-cinc docents d'educació infantil que desenvolupen pedagogies alternatives a l'aula en la província de Castelló (Espanya). El que es pretén conèixer és: 1) Com treballen a l'aula? Quines són les seues pràctiques, els espais d'aprenentatge, la gestió del temps, els recursos que utilitzen, les estructures d'agrupaments, els continguts curriculars, la metodologia i l'avaluació? 2) Per què ho fan així? Quines creences, actituds, valors, percepcions i experiències tenen? 3) Quin rol juguen els infants i l'adult en les pedagogies alternatives?
\end{abstract}

MÈTODE. La metodologia ha sigut qualitativa. Es tracta d'un estudi descriptiu. La informació s'ha recollit mitjançant trenta-cinc entrevistes semiestructurades i s'ha analitzat mitjançant la ferramenta ATLAS.ti.

RESULTATS. Els resultats donen veu als docents d'educació infantil, els quals expliquen com porten a terme les pràctiques d'aula seguint els principis i elements de les pedagogies alternatives.

CONCLUSIÓ. En les conclusions es pot veure com els docents es troben en un canvi per desenvolupar i materialitzar, en la seua aula, els principis de les pedagogies alternatives. Tot açò suposa un canvi de mirada cap a l'infant, per tal d'avançar cap a l'escola que volen.

Paraules clau

Pedagogies alternatives; Pràctica docent; Docents; Educació infantil; Recerca qualitativa.

Dades de les autores

${ }^{1}$ Universitat Jaume I, Espanya.

${ }^{2}$ Universitat Jaume I, Espanya. Professora ajudant doctora tipus II en el Departament de Pedagogia i Didàctica de les Ciències Socials, la Llengua i la Literatura. Adreça de contacte: asanahuj@uji.es

Referència recomanada

Benages-Garcia, L, i Sanahuja-Ribés, A. (2021). Pedagogies alternatives i pràctiques d'aula en educació infantil: la veu dels docents. REIRE Revista d'Innovació i Recerca en Educació, 14(1), 1-18. https://doi.org/10.1344/reire2021.14.132266

(c) 2021 Les autores. Aquest article és d'accés obert subjecte a la llicència de Reconeixement 4.0 Internacional Creative Commons, la qual permet utilitzar, distribuir i reproduir per qualsevol mitjà sense restriccions sempre i quan se citi adequadament l'obra original. Per veure una còpia de la llicència, visiteu https://creativecommons.org/licenses/by/4.0/ 


\section{Título (castellano)}

Pedagogías alternativas y prácticas de aula en Educación Infantil: la voz de los docentes

\section{Resumen}

INTRODUCCIÓN. El presente artículo tiene como propósito indagar sobre las prácticas de 35 docentes de educación infantil que desarrollan pedagogías alternativas en el aula en la provincia de Castellón (España). Se pretende conocer: en primer lugar ¿Cómo trabajan en el aula?, en este artículo se describen sus prácticas, dando a conocer el espacio, la gestión del tiempo, los recursos que utilizan, las estructuras de agrupamientos, los contenidos curriculares, la metodología y la evaluación que siguen; en segundo lugar ¿Por qué lo hacen así? ¿Qué creencias, actitudes, valores, percepciones y experiencias tienen?; para terminar ¿Qué rol juegan los niños y el adulto en las pedagogías alternativas?

MÉTODO. La metodología ha sido cualitativa. Se trata de un estudio descriptivo. La información ha sido recogida mediante 35 entrevistas semiestructuradas y analizadas mediante la herramienta ATLAS.ti.

RESULTADOS. Los resultados dan voz a los docentes de educación infantil, los cuales explican cómo llevan a cabo las prácticas de aula siguiendo los principios y elementos de las pedagogías alternativ.

CONCLUSIÓN. En las conclusiones se puede ver como los docentes están en proceso de cambio para desarrollar y materializar, en su aula, los principios de las pedagogías alternativas. Todo esto supone un cambio de mirada hacia el niño, para avanzar hacia la escuela que quieren.

\section{Palabras clave}

Pedagogías alternativas; Práctica docente; Docentes; Educación infantil; Investigación cualitativa.

\section{Title (English)}

Alternative pedagogies and classroom practices in early childhood education: the voice of the teachers

\section{Abstract}

INTRODUCTION. The aim of this paper is to examine the classroom practices carried out by 35 early childhood teachers in the region of Castellon (Spain) who apply alternative pedagogies. The focus will be: 1) How do these early childhood teachers work in the classroom? How do they describe the use of the space, the time, the means, the grouping structures, the curricular content, the methodology and the evaluation? 2) Why do they do things in this way? What are their believes, attitudes, values, perceptions, and experiences? What roles do the children and adults play in these alternative pedagogies?

METHOD. This descriptive study applies a qualitative methodology. The information was collected through 35 semi-structured interviews and analyzed with the ATLAS.ti tool.

RESULTS. The results reflect the views of the early childhood teachers who explain how they apply these alternative pedagogies in the classroom.

CONCLUSION. The conclusions show how the teachers apply alternative pedagogies in the classroom. These practices entail a change of attitude towards the child in the process of establishing the kind of school that the teachers want.

\section{Keywords}

Alternative pedagogies; Teaching practices; Teachers; Pre-school; Qualitative research. 


\section{Introducció}

Les pedagogies alternatives s'entenen com una alternativa al que és tradicional o convencional (García, 2017). Pot ser que siguen alternatives a la insatisfacció amb l'escola tradicional, en què cal buscar noves mirades i maneres d'ensenyar i aprendre (Carbonell, 2019). No obstant això, es tracta d'un debat no resolt ni exempt de dilemes, ja que aquestes pedagogies no són noves i fa anys que s'han desenvolupat, encara que només una minoria les porta a terme a l'aula. Per tant, en lloc d'identificar una pedagogia tradicional o unes pedagogies innovadores, convé centrar-se en la posició que ocupen el docent i l'alumnat en el procés d'ensenyança-aprenentatge (Brailovsky, 2018). Per a Zarrias (2019) la base d'aquestes pedagogies recau en el canvi de mirada cap a l'infant, un canvi de paradigma en què és el protagonista del seu propi aprenentatge. Tanmateix, Ferri (2019) afegeix que cal fer una profunda reflexió sobre les raons i els principis cap als quals es volen orientar els processos educatius. En paraules de Díaz (2019), les pedagogies alternatives en molts casos són una influència i reinterpretació dels plantejaments de l'Escola Nova (finals del segle xix). Podem trobar pedagogues i pedagogs de referència com Maria Montessori, Loris Malaguzzi, Célestin Freinet, Ovide Decroly, Pestalozzi, Rosseau, Rudolf Steiner (Waldorf), les germanes Agazzi, Dewey o Rebeca i Mauricio Wild, entre d'altres. A l'Estat espanyol, i més concretament a Catalunya, cal destacar les aportacions de Rosa Sensat, qui va ser directora de la secció de xiques de la primera escola del bosc a Montjuïc, va difondre les seues experiències renovadores, les seues concepcions i els seus ideals educatius (Moreno, 2013). Agafant com a referència Carbonell (2019, p. 99):

Les pedagogies i escoles lliures no directives que, en la majoria dels casos, s'han anat creant durant l'últim terç del segle $x \mathrm{x} i$ en el transcurs d'aquest tenen diversos orígens i prenen diferents orientacions, però es fonamenten en un objectiu comú: el respecte al procés del lliure desenvolupament de la infància, la confiança en la possibilitat de construir-se a si mateixa i la no interferència per part de les persones adultes en les eleccions i decisions que vagi prenent en la seva marxa educativa.

\subsection{L’acte pedagògic: algunes aportacions i elements clau}

Les pedagogies alternatives es basen en un aprenentatge vivencial i actiu, en què la manipulació, l'experimentació, l'escolta activa i el joc són elements clau, i en què es tenen en compte les vivències emocionals, ja que són les que constitueixen la base del desenvolupament. Montessori ja fomentava l'aprenentatge mitjançant l'experimentació i la manipulació, però sempre des de la motivació intrínseca dels infants, oferint-los llibertat i respecte i fomentant la seua autonomia (García, 2017; Muñoz, 2017). En la mateixa línia, l'educació viva es basa en un aprenentatge autodirigit i autònom, que fa que es produïsca la curiositat de l'infant mateix. L'escolta activa també és un element important: per exemple, en l'enfocament de Reggio Emilia la pedagogia de l'escolta té un paper fonamental perquè desenvolupa la principal característica d'escoltar-se un mateix i escoltar els altres (García, 2017). Per a Jordi Mateu, director del CAIEV (Centre d’Assessorament i Investigació d'Educació Viva) i de l'escola Ca l'Aulet, l'educació viva i activa és una proposta pedagògica dins de l'enfocament globalitzat, però que va més enllà incorporant la integració i la complexitat que formen els aspectes educatius (CAIEV, s. d.). Així mateix, el joc és un altre element que cal destacar. Per a L’Ecuyer (2014) el joc és gaudir en la realització de la tasca, ja que és on l'infant posa la seua atenció, la seua imaginació, la seua creativitat, fins a interioritzar-la i fer-la seua. Per tant, l'infant aprèn a través del seu entorn mitjançant l'experimentació amb els seus sentits. Aquesta idea també és present en la pedagogia Waldorf (Cardoso i García-Torralba; 2018; Díaz, 2019) i en les aportacions de Rebeca Wild (García, 2017). Així, el joc proporciona seguretat en els infants (Stern, 2017), però 
cal ser conscients que, com bé deia Montessori, qualsevol ajuda innecessària els és un obstacle en el seu desenvolupament (García, 2017).

Altres elements a tindre en compte són els espais d'aprenentatge i la gestió del temps i dels recursos humans i materials. Quant a l'organització de l'espai, aquest ha de ser multifuncional i variable; els infants han de poder moure-s'hi, observar, experimentar i manipular objectes. L'aula es concep com un taller o un laboratori, perquè es treballa en grups i es fomenta la interacció entre els infants (Trilla i Puig, 2003). En l'enfocament de Reggio Emilia es cuida l'estètica i la bellesa dels espais, així com el mobiliari, l'organització dels elements i dels objectes, que han d'estar sempre a l'abast, a més de la Ilum i dels colors, seguint la filosofia de l'atelier (Silvente, 2017). Per a Trueba (2015) l'espai ha d'estar en una transformació constant, en el sentit que s'ha d'adaptar a les necessitats dels infants; ha de ser un espai viu en continu canvi. En les escoles Waldorf es valora molt l'espai exterior, ja que els infants passen la major part del temps fora de l'aula, pràctica que els permet desenvolupar el sentiment per la naturalesa (García, 2017). Aquesta mateixa idea també va ser impulsada per Rosa Sensat (Moreno, 2013).

Quant al temps, aquest es caracteritza per ser flexible i lliure (Trueba, 2015) i per potenciar l'autonomia dels infants. Albert (2019) també pensa que és molt important planificar des de la flexibilitat $i$ des de les necessitats que tenen els infants $i$, a més, puntualitza que el temps és fonamental en els primers anys de vida. D'altra banda, Estremeda (2018) afirma que l'infant aprèn seguint els seus desitjos, les seues motivacions i les seues necessitats i que ho fa al seu ritme. També fa menció que no ha d'haver-hi un temps definit per a fer qualsevol activitat, sinó que és l'infant el que decideix el temps que necessita.

Sobre els recursos humans, des de la pedagogia Waldorf, per exemple, es fomenta un treball cooperatiu i una relació molt estreta amb les famílies (Cardoso i García-Torralba 2018). En aquest sentit, Trueba (2015) afirma que la relació de les famílies en els models d'escoles com les de Reggio Emilia es planteja des d'un model interactiu i dialogant. Els recursos materials que utilitzava Montessori eren autocorrectius, sensorials i manipulatius amb l'objectiu de potenciar l'autonomia i l'autoestima dels infants, perquè els feia adonar-se de les errades (Díaz, 2019; García, 2017). Pel que fa als materials manipulatius, Muñoz (2017) afirma que són cabdals per a la connexió dels dos hemisferis cerebrals, i a banda promouen l'aprenentatge vivencial, molt ric en la primera infància. Per a Rebeca Wild (2011) era important que els materials estructurats tinguessin una presentació atractiva i vistosa, i que els materials no estructurats es caracteritzaren pel factor sorpresa.

Pel que respecta a l'avaluació i l'evolució de l'infant en el seu procés d'aprenentatge, segons Jové (2017) es tracta d'un procés constant que permet veure el seu desenvolupament i així poder personalitzar i ajustar el currículum a les seues necessitats i ritmes per tenir un aprenentatge òptim. En les escoles de Reggio Emilia un aspecte clau és documentar en tot moment els processos i l'evolució que tenen els infants en els seus propis aprenentatges, a fi d'oferir una informació més completa a l'adult (Díaz, 2019). En aquestes escoles s'anota qualsevol observació sobre fets rellevants que passen durant el dia a dia, i aquesta informació es comparteix amb tots els professionals que intervenen en l'educació dels infants (Bersaluce, 2009). Davoli (2016) comenta que documentar és fer visibles els processos, i que amb aquesta documentació el que es fa és fer un retrat de cada infant. Les tècniques $i$ els instruments que s'utilitzen per fer l'avaluació són l'observació directa, en què anoten la informació en les plantilles i en els registres, i les memòries i els informes que fan servir al finalitzar el procés. 


\subsection{El rol dels infants i de l'adult en el procés d'ensenyança-aprenentatge}

Totes aquestes pedagogies alternatives tenen uns principis comuns, els quals parteixen de la concepció de l'infant com a protagonista dels seus aprenentatges. Aquests aprenentatges succeeixen en un entorn on els seus interessos, motivacions i ritmes són respectats $i$ tot parteix de I'infant (Alabart, 2017; Cardoso i García-Torralba, 2018; García, 2017; Malaguzzi, 2011; Silvente, 2017). Un dels principals objectius es basa en l'educació integral, en què es fomenta la creativitat, la participació i el pensament crític, així com l'expressió, el diàleg i la presa de decisions (Díaz, 2019). Com que aquestes pedagogies fomenten la cooperació i no la competitivitat, entenent que cada infant té un ritme, cal buscar solucions perquè puguen aprendre tots junts. Aquestes pedagogies estan a favor que infants de diferents edats i interessos compartisquen aula, i això és també una manera de fomentar la col-laboració entre ells i que es valore més la diversitat (García, 2017). Quant a la visió de l'infant, L'Ecuyer (2014) el descriu com una persona original que inicia el seu procés $d$ 'aprenentatge des de dins, de manera que li atribueix una sèrie d'objectius com a persona curiosa, descobridora, inventora i formuladora d'hipòtesis. La identitat de l'infant parteix del seu jo, que es crea a partir de la interacció amb els altres, i, per tant, es va construint a partir de la interacció que té amb les relacions quotidianes, en què fa seus una sèrie de valors, actituds i creences (Riba, 2019).

Sobre el rol del professor, Zarrias (2019) diu que passa a ser un acompanyant dels processos d'ensenyança-aprenentatge que es desenvolupen en un ambient o un espai. Al mateix temps, és considerat com un observador directe sobre tot el procés d'aprenentatge de l'infant mentre li ofereix seguretat, empatia i respecte. En la pedagogia Montessori és vist com un guia actiu que es dedica a la preparació dels ambients (García, 2017), i en la pedagogia Waldorf no és considerat un guia, sinó un model de referència que l'infant pot imitar (Díaz, 2019). Tanmateix, Altimir $(2017,2019)$ comenta que en Reggio Emilia l'adult està constantment observant i documentant els processos dels infants, i que ho fa per donar visibilitat a l'acció, als processos de coneixement, i per discutir i interpretar la realitat que s'ha construït amb els infants. Per altra banda, en l'educació viva l'acompanyament ha de ser no directiu $i$, al mateix temps, ha d'estar atent a les observacions per a conèixer les necessitats i les potencialitats que proporcionen uns estímuls i un vincle afectuós amb l'infant. Per tant, en l'educació viva el paper que té és el d'acompanyar en tot moment el procés d'ensenyançaaprenentatge (Alabart, 2017). Riba (2019) entén el rol del mestre com un acompanyant dels infants en els processos de recerca, d'experimentació, de desenvolupament i de descoberta del món; així, la seva manera d'educar ha d'incloure experimentació, descoberta, recerca i reflexió de la seua pràctica docent.

L'objectiu principal que es planteja en aquesta investigació és explorar les pràctiques educatives de trenta-cinc docents d'educació infantil que desenvolupen pedagogies alternatives en les seues aules. Aleshores ens preguntem: 1) Com treballen a l'aula? Com són els espais d'aprenentatge, la gestió del temps, els recursos que utilitzen, les estructures d'agrupaments, la metodologia i l'avaluació? 2) Per què ho fan així? Quines creences, actituds, valors, percepcions i experiències tenen? 3) Quin rol juguen els infants i l'adult en les pedagogies alternatives?

\section{Mètode}

El disseny d'aquesta investigació s'ha basat en una metodologia qualitativa. Segons Sandín (2003) la recerca qualitativa es caracteritza per ser una activitat sistemàtica orientada a la comprensió de fenòmens 
educatius i socials amb el propòsit de descobrir i desenvolupar un cos organitzat de coneixements. Més específicament, es tracta d'un estudi descriptiu (Bisquerra, 2004) que se centra en les pràctiques d'aula de docents de la província de Castelló (Espanya).

\subsection{Participants}

La selecció de participants va ser el resultat d'un mostreig intencional per conveniència i criterial. Els criteris de selecció van ser els següents: 1) docents en actiu d'educació infantil que utilitzen pedagogies alternatives a l'aula, 2) que tinguen com a mínim un any d'experiència docent en l'ús de les pedagogies alternatives, 3) que siguen de la província de Castelló (Espanya, context pròxim), 4) que participen en projectes d'innovació educativa o formen part del moviment de renovació pedagògica (MRP) i 5) que siguen reconeguts pels companys i companyes com a referents en l'ús de pedagogies alternatives.

Els participants han sigut un total de 35 docents d'educació infantil, dels quals pràcticament tots eren dones: $34(97,14 \%)$ dones i 1 (2,85\%) home. Quant a l'edat d'aquests docents, n'hi ha 8 $(22,85 \%)$ d'entre 25 i 30 anys, 12 (34,28\%) d'entre 31 i 40 anys, 8 (22,85\%) d'entre 41 i 50 anys i 7 (20 \%) de més de 51 anys. Amb relació als anys d'experiència docent, $8(22,85 \%)$ tenen d'1 a 4 anys d'experiència, 7 (20\%) tenen de 5 a 9 anys d'experiència, $6(17,14 \%)$ tenen de 10 a 14 anys d'experiència i 14 (40\%) tenen més de 15 anys d'experiència. A més a més, cal indicar que 9 $(25,71 \%)$ treballen en el primer cicle d'educació infantil (de 0 a 3 anys) i $26(74,29 \%)$ treballen en el segon cicle d'educació infantil (de 3 a 6 anys).

\subsection{Instrument i procediment de la recerca}

En un primer moment es va elaborar un guió d'una entrevista semiestructurada amb preguntes obertes per estudiar quines pedagogies alternatives i pràctiques docents es fan en educació infantil. Seguint Bisquerra (2004), les entrevistes semiestructurades són aquelles que parteixen d'un guió previ, i obertes perquè permeten extraure la informació més rellevant $\mathrm{i}$ important, alhora que permeten construir coneixements holístics amb la finalitat d'apropar-se millor a la realitat.

Així, l'entrevista es va estructurar en dos nivells: 1) Com treballen? Descripció de les seues pràctiques i 2) Per què ho fan així? Creences, actituds, valors, percepcions i experiències. En el primer bloc, les preguntes de l'entrevista giraven al voltant dels següents elements: $a$ ) pedagogs o pedagogues de referència i ús de pedagogies alternatives, $b$ ) el temps (període d'acollida), els espais i els recursos humans i materials, $c$ ) agrupaments $i$ interacció entre l'alumnat a l'aula, $d$ ) la metodologia i el joc, $e$ ) l'avaluació i $f$ ) el paper de l'infant i de l'adult.

Cada una de les entrevistes va tenir una duració aproximada d'entre 30 i 50 minuts. Tota la informació va ser gravada fora de l'horari lectiu per als mestres, amb l'objectiu de no interferir en el seu dia a dia en l'aula. Aquestes entrevistes van ser transcrites de manera literal. Posteriorment, es va passar a l'anàlisi de les dades per reduir-les i interpretar-les (Miles i Huberman, 1994). Es va seguir una lògica deductiva i inductiva. L'anàlisi es va fer mitjançant el programari ATLAS.ti, versió 8. 


\subsection{Qüestions ètiques de la investigación}

Abans de recollir les dades, cada participant va signar un consentiment informat (basat en la proposta de Sales et al., 2019) en què es comunicava que la seua col-laboració en l'estudi era voluntària, sempre respectant i garantint la seua privacitat i confidencialitat. A més a més, per respectar el seu anonimat s'han utilitzat abreviatures i números.

\section{Resultats}

En aquest apartat es mostren els resultats de l'anàlisi duta a terme atenent al contingut semàntic de les diferents unitats d'anàlisi. Amb el propòsit de presentar els resultats de manera clara i ordenada, a continuació es mostra un mapa conceptual elaborat amb la ferramenta CmapTools (vegeu la figura 1).

\section{Figura 1}

Mapa dels resultats de l'anàlisi de contingut de tipus semàntic

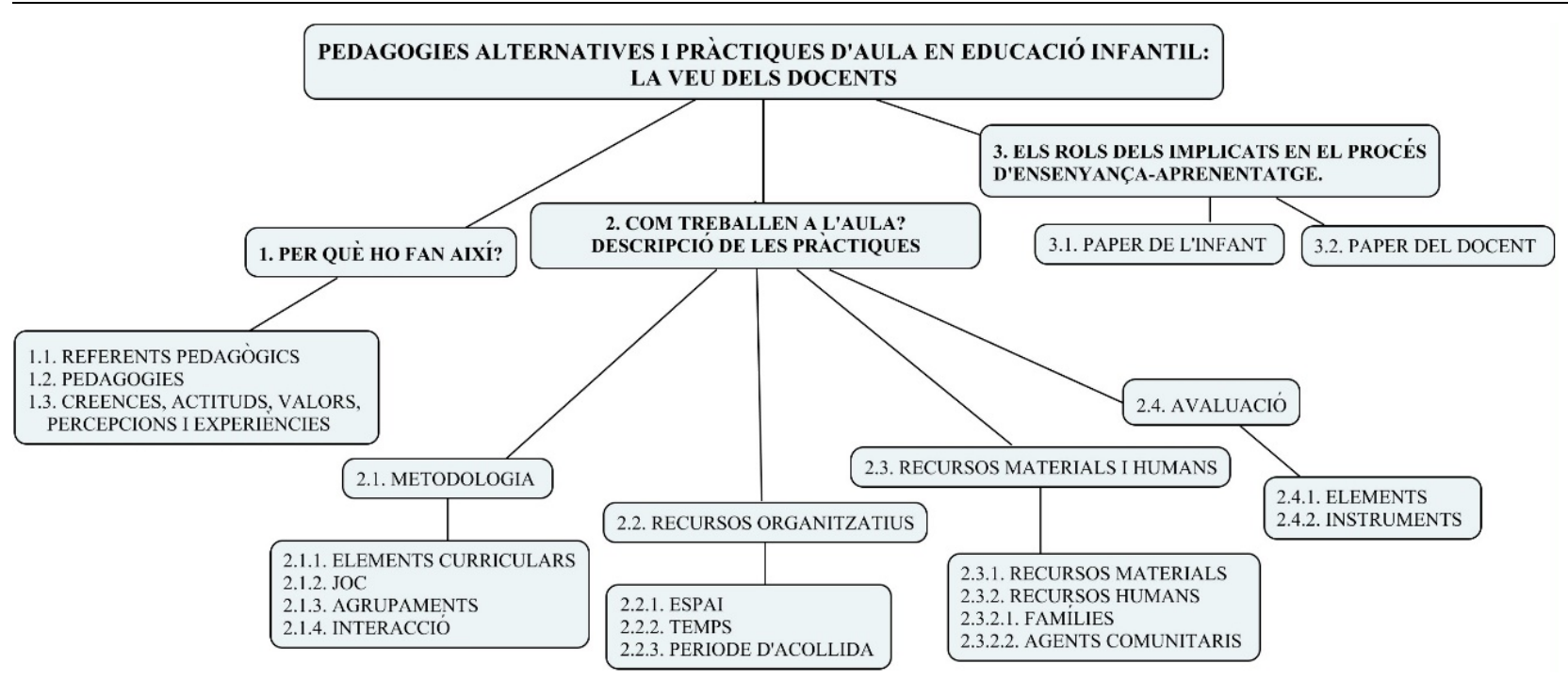

El mapa presenta de manera simplificada tota la informació que s'ha extret de les entrevistes fetes als mestres i l'organitza en tres eixos principals. S'han recollit un total de $419(100 \%)$ cites, distribuïdes en les diferents categories d'anàlisi. En el primer eix està la pregunta «Perquè ho fan així?», en la qual es fa referència als referents pedagògics amb un $8,11 \%(34)$, a les pedagogies que utilitzen a l'aula amb un $5,96 \%$ (25) i a les creences, actituds, valors, percepcions i experiències amb un 9,55 \% (40).

En el segon eix, "Com treballen a l'aula?», es troba en primer lloc la metodologia, amb un 6,20\% (26) de resposta, i dins d'aquesta estan els elements curriculars amb un 4,77\% (20), el joc amb un $5 \%(21)$, els agrupaments amb un 5,8\% (25) i la interacció amb un 2,86\% (12). En segon lloc trobem els recursos organitzatius, amb un 19,95\% (71) de resposta, i dins d'aquests trobem l'espai amb un 8,35\% (35) de resposta, el temps amb un 4,3\% (18) i el període d'acollida amb un 4,3\% (18). En tercer lloc estan els recursos materials, amb 8,35\% (35) de resposta, i els recursos humans, que es divideixen en les famílies, amb un 5 \% (21), i els agents comunitaris, amb 4,1 \% (17). En quart lloc està l'avaluació, amb un 6,44 \% (27) de resposta. 
En el tercer eix, «Els rols dels implicats en el procés d'ensenyança-aprenentatge», es troba el paper dels infants amb un 5,25\% (22) de resposta i el del docent amb un 5,55 \% (23).

\subsection{Per què treballen així?}

En primer terme, és necessari saber quins referents pedagògics tenen els informants, si $s^{\prime}$ identifiquen amb algun pedagog o pedagoga, quines pedagogies apliquen a l'aula i quines creences, actituds, valors, percepcions i experiències els han portat a treballar d'aquesta manera.

Podem veure com la majoria dels docents han tingut $\mathrm{i}$ tenen algun referent present en la seua vida. Diversos informants destaquen les aportacions de Loris Malaguzzi i la seua proposta dels cent llenguatges:

El projecte de Loris Malaguzzi per a mi és un projecte molt complet, perquè no és una pedagogia, és un projecte educatiu. [...] Té una base científica i pedagògica molt important $i$ a mesura que vaig llegint $i$ vaig aprofundint, més em va agradant. [...] Ell s'ha nodrit de Vigotski. Aleshores me fa anar a Vigotski. Dewey també està en la seua base, que són els projectes de treball. Resulta que al seu projecte també està Freinet. (E20)

Un altre informant s'identifica amb Malaguzzi per la seua mirada tan especial cap als infants i el valor que li dona: "Perquè considere que és un dels pedagogs que realment va mirar a l'infant com I'havíem de mirar. En una mirada més tendra, una mirada capaç; això és el que més em crida d'ell. Després, el respecte cap a l'infant» (E24).

Una altra informant situa Freinet com el seu màxim referent:

Freinet va ser qui em va obrir el món de l'educació. Aleshores eixe pedagog el tinc molt present perquè era un mestre rural d'una escola de poble i per al poble, una escola molt democràtica en què donava molt la veu als infants. (E18)

Tanmateix, un altre entrevistat menciona Rosa Sensat com la base de la seua formació: «Rosa Sensat, ella i la seua filosofia de canvi a les escoles infantils de Catalunya, va ser la base de la meua formació i la constatació que una altra manera de fer escola és possible» (E14).

A més a més, expliquen quins altres referents han anat trobant en el seu dia a dia mitjançant la formació continuada: «M'agrada Maria Antònia Canals per la seua metodologia d'aprendre les matemàtiques, Heike Freire perquè és molt de la natura i Catherine L'Ecuyer perquè l'escola ha de ser com la vida» (E18).

D'altra banda, també hi ha informants que no s'identifiquen amb cap pedagog en concret: «El que faig és agafar el que m'agrada de cadascun i ho vaig aplicant. També pense que cada classe i cada context són diferents i van canviant els infants» (E26), o "En molts, però depèn, perquè et mires en una o en una altra. En l'àmbit de la pràctica docent partiria de la pedagogia viva de Mauricio i Rebeca Wild, i de Loris Malaguzzi en la pedagogia de Reggio Emilia» (E30).

Per seguir responent a la primera qüestió principal, després de veure amb quins pedagogs o pedagogues s'identifiquen, cal conèixer quines pedagogies alternatives utilitzen en el seu dia a dia a I'aula. Com es pot veure, per alguns docents és molt important que la pedagogia done resposta a les necessitats i els interessos dels infants sense cap imposició: 
Em base molt en la pedagogia de l'asombro o sorpresa segons Catherine L'Ecuyer, qui considera que l'aprenentatge, per a ser productiu, ha de sorgir de dins cap a fora, i no al contrari. Ha de respondre a les necessitats i interessos dels infants, i no estar imposat des de fora. (E2)

$\mathrm{Hi}$ ha informants que agafen el que més els agrada de cada pedagogia: «Reggio Emilia per la importància que crec que té fomentar l'esperit indagador en els xiquets, però també Montessori per tal de fomentar l'autonomia i Waldorf per la seua creativitat i tendència a la utilització de recursos naturals» (E8), o "Montessori sobretot per a l'estructuració de materials i Pikler per al moviment lliure, la psicomotricitat i la mirada de l'educació viva i activa pel missatge, l'observació, l'evolució i l'acompanyament emocional» (E13).

Seguint en la mateixa línia, queda clar que l'infant ha de ser el protagonista de tots els seus aprenentatges, per això a l'hora de basar-se en una pedagogia o en una altra sempre es mira cap a I'infant: «El que sí que tenim clar és que el xiquet ha de ser el protagonista del seu propi aprenentatge; hem de deixar-lo ser ell mateix» (E24).

Pel que fa a les creences, actituds, valors, percepcions i experiències dels entrevistats, aquestes s'han vist modificades i reflexionades a causa de la seua trajectòria per l'educació. Alguns han fet un anàlisi del que passava en el seu dia a dia:

Després de fer un treball exhaustiu d'anàlisi del currículum del segon cicle d'infantil ens vam adonar, les mestres del cicle, que el treball amb fitxes i més dirigit no atenia el que establia el decret ni tampoc s'adaptava als infants. En canvi, avui dia la nostra metodologia està més adaptada al que estableix el currículum i també a les necessitats, ritmes i característiques dels infants d'aquesta etapa. (E1)

A uns altres participants l'experiència docent els ha fet reflexionar al llarg de tota la seua trajectòria i la insatisfacció amb el que feien abans:

Jo vaig començar a veure que la cosa no m'agradava perquè estaven moltes hores asseguts, moltes hores fent tots el mateix, i arribàvem a moments que hi havia xiquets que anaven molt bé, però hi havia xiquets que es despenjaven molt. (E12)

Seguint amb el canvi de mirada cap a l'infant, un informant va decidir no seguir amb el que estava fent fins ara: "En un moment de la meua vida professional vaig dir: "No he de mirar cap allà, he de mirar-los a ells, escoltar [...] el que necessiten"» (E20).

Verbalitzen que la creença de cadascú és molt important per a seguir treballant: «Si hi ha alguna cosa que $m$ 'ha acompanyat al llarg de la meua docència és creure que ells tenen moltes capacitats, que nosaltres tenim la responsabilitat i el deure d'afavorir, de traure el millor de cadascú» (E11). Per altra banda, també hi ha un informant que fa menció al sentit comú, al respecte i a la confiança:

El puntal bàsic en la meua pràctica docent és el sentit comú, el respecte i confiança en la persona que tinc al davant, [...] quina és la necessitat que observe de la criatura i com li done resposta i acompanye. (E17)

Aleshores, com diu un informant, el canvi de mirada del docent cap a l'infant ha de ser un dels principals elements en l'educació:

Els docents no som el centre ni els protagonistes del procés d'aprenentatge; són les criatures. Si ens basem en això, tot allò que suposa el dia a dia a l'escola hauria d'estar basat en els seus interessos i habilitats, impregnades sempre del joc, la sorpresa i el descobriment per a motivar els infants i que ells passen a ser, de forma autònoma, els protagonistes del seu procés d'aprenentatge. (E17) 
També fan menció al sistema educatiu que hi ha i a la necessitat que es té d'un canvi en l'educació: «El sistema educatiu està obsolet. Una societat com la nostra necessita un altre tipus d'educació i aprenentatges» (E5).

\subsection{Com treballen? Descripció de les practiques d'aula}

La segona qüestió que s'aborda és com treballen, que respon a la descripció de les pràctiques en l'aula, tenint en compte els elements principals: els continguts curriculars, la metodologia, els espais i el temps, els recursos materials i humans i l'avaluació.

Respecte a l'adaptació dels continguts curriculars en aquestes pedagogies, trobem que cada docent ho fa d'una manera. Alguns tenen en compte el currículum:

Ens mostra els continguts a treballar, però no determina una única manera de fer-ho, tot i que aquestes pedagogies responen a l'enfocament globalitzador, al sentit i significativitat de l'aprenentatge, a tenir en compte les experiències de l'alumnat i a fer ús del joc per aprendre, aspectes fonamentals del nostre currículum. (E3)

D’altres diuen que el currículum es complix de manera natural: «És molt bàsic, i els nadons el complixen pràcticament sense que els adults els fem res [...]. Més que deixar fer, es van treballant de manera totalment espontània» (E13), «Si els llegeixes bé es compleixen sols» (E15), «Si tu et lliges el currículum t'adones que no tenim cap problema, [...] no adapte res, sorgix i està en el dia a dia» (E20). Per altra banda, es pot veure com el currículum el tenen en compte una vegada que s'han fet les propostes o mentre estan aprenent a través del joc: "La forma que tinc d'adaptar aquesta pedagogia perquè el meu alumnat assolisca els continguts curriculars és aprendre a través del joc lliure i/o suggerit» (E2), o "El que faig és que de les propostes que de manera instintiva ixen dels xiquets al final quan hem tancat el cicle, la investigació o el projecte, comprove quines són les que han treballat, no les adapte, no les busque en el decret, què és el que estan fent, sinó que quan hem acabat jo busque què és el que han aconseguit» (E6).

Pel que fa a la metodologia, es pot dir que és el camí per obtenir els objectius i els continguts programats; fa referència a com ensenyar. També podem dir que és el conjunt de decisions que prenen els mestres per a configurar la intervenció educativa en les diferents situacions del procés d'ensenyança-aprenentatge. Un informant conta quina és la principal estratègia metodològica que utilitza: "La principal estratègia d'aprenentatge és el joc presentat en propostes manipulatives, experimentals i, majoritàriament, autocorrectives. També els propose conflictes que els posen en dubte els seus coneixements i els porten a modificar-los i ampliar-los» (E3).

Un altre informant afirma que utilitza «una metodologia vivencial, basada en el joc, que [faça que] aprenguen tocant, experimentant, i donant el temps necessari, mitjançant qualsevol dels llenguatges» (E4). Així mateix, un altre comenta:

Utilitze un plantejament constructivista, a partir del qual els aprenentatges es van construint a través de l'activitat de l'alumnat, [...] a partir del desenvolupament de l'alumnat, la globalització de l'ensenyament, la construcció d'aprenentatges significatius, el joc com a base de l'aprenentatge, la socialització i el treball en equip o tenint en compte la motivació $i$ els interessos dels infants. (E7)

Per altra banda, un informant apunta: «No tinc un mètode específic, sí una visió educativa: un enfocament globalitzador, un aprenentatge significatiu, una metodologia viva i activa, arrelada a l'entorn pròxim» (E11). És important generar contextos rics d'aprenentatge: «M'interessa crear 
contextos rics d'aprenentatge, perquè l'alumnat avance per si mateix. Plantejar-los reptes i preguntes que els facen pensar, observant les situacions que es van produint» (E23). La base és el constructivisme i així ho explica un entrevistat: «Construir el propi aprenentatge per ell mateix, $\mathrm{i}$ nosaltres acompanyar-lo. Eixa és la metodologia més important per a nosaltres, la construcció» (E24). L'acció espontània és un punt important en l'infant i al mateix temps per a l'adult, perquè li proporciona més informació: "Partim de l'acció espontània partint dels materials que els anem oferint i intentant estirar un poc la corda [...]. És una metodologia basada en l'acció espontània i lliure de l'infant» (E30).

Pel que fa al joc, els mestres d'educació infantil el consideren bàsic en la vida de l'infant i així ho manifesten: «El joc és fonamental, és motivador i atractiu per als infants; a més, el grau de dificultat es pot adaptar a les necessitats de cadascú» (E1). Hi ha un informant que té molt present un pedagog que dona molta importància al joc en la primera infància:

Segons afirma el pedagog i il-lustrador Francesco Tonucci, els aprenentatges més importants en la primera infància del xiquet i xiqueta es realitzen jugant. Per tant, el joc és una actitud innata dels infants mitjançant la qual descobreixen el seu entorn més pròxim i els seus elements. (E2)

També descriuen el joc com la base dels aprenentatges de tota activitat que fa l'infant: «És la base del procés d'ensenyament-aprenentatge; tota activitat parteix d'aquest punt. [...] Considere el joc una part fonamental del dia a dia en els infants» (E7). Per altra banda, el joc ajuda a desenvolupar altres aspectes: «Quan poden desenvolupar el seu llenguatge, la seua creativitat, se relacionen amb els companys, [...] el joc és la seua manera de viure» (E22).

Com bé explica un docent, s'ha de tenir en compte que no hi ha diferència entre jugar i treballar: «Per a mi quan els infants estan jugant a gust, ahí hi ha un aprenentatge espectacular; per tant, jo partisc sempre del joc com a eina per a l'aprenentatge» (E30). També es pot veure la reacció d'un entrevistat qui manifesta que el docent ha de ser conscient del que està oferint i saber en tot moment quin és el seu paper:

Jugar en infantil no és perdre el temps, jugar és aprendre. El que passe és que no tot s'hi val. Vull dir, els xiquets han de jugar, però tu com a mestra has de tindre molt clar què els oferixes i què pots traure d'ahí, perquè l'alumne és cert que pot jugar $\mathrm{i}$ aprendre molt, però tu també has de ser conscient del que està aprenent o oferir-li altres reptes perquè continue en el joc que li agrade, potenciar eixos aprenentatges que puga fer. (E29)

Pel que fa a les estructures d'aprenentatge i als agrupaments, els informants tenen en compte que els infants interaccionen a l'aula. "Aprenentatge entre iguals i aprenentatge cooperatiu» (E3) i, a més a més, les interaccions que de forma espontània ixent d'ells: "Les interaccions es donen de manera natural i espontània [...]. Cal regular els intercanvis per a afavorir una bona expressió i comprensió dels missatges» (E10). Per aquest informant deixar obertes les portes de l'aula fomenta la interacció amb la resta d'infants que hi ha en l'escola: «Portes obertes a la interacció. Llibertat de moviment, sempre amb la seguretat de la presència de les acompanyants» (E14). Quant als agrupaments dels infants, els docents entrevistats tenen en compte molts aspectes, com ara «les característiques, la personalitat i els interessos dels infants, per tal de trobar grups que a més d'aprenentatges generen reptes, noves relacions i col-laboració entre ells» (E1). Els tipus d'agrupaments que se solen fer en educació infantil són molts i variats i, a més, els criteris per escollir un o l'altre depenen molt del que es vulga fer. Així ho explica un informant: 
Grup classe, gran grup, petit grup, parelles i individual. Els faig que siguen heterogenis. Els criteris depenen del que vull realitzar: aplique un criteri o un altre, però quasi sempre [intente] afavorir l'autonomia, compensar diferències maduratives, afavorir relacions, desvincular relacions de dependència, mixtos. També intente mirar el nivell de maduració perquè en aquestes edats hi ha molta diferència entre uns xiquets i uns altres. Xiquets que tenen molt desenvolupat el llenguatge i altres que l'hi tenen poc. Així uns aprenen dels altres. (E22)

Tanmateix, i en la mateixa línia, un altre informant verbalitza: «Els agrupaments són lliures i són els infants els que decideixen [...]. Els criteris: grups heterogenis pel que fa a nombre de xiquets $\mathrm{i}$ xiquetes, caràcters, ritmes maduratius, relacions de dependència positives o negatives» (E5).

Per a desenvolupar les activitats del dia a dia que es porten a terme en una escola, és important l'espai físic. A l'hora de distribuir-lo, cada docent té en compte la realitat de l'escola i sobretot la de l'aula, que és on els infants passen la major part del dia a dia. Com manifesta un informant: "L'espai físic que més utilitze és l'aula del meu grup d'alumnes. És un espai constituït per diferents zones on els infants puguen jugar $i$ estar alguns moments acompanyats de l'adult $i$ altres moments tots sols» (E4).

Com que cada grup d'infants és diferent, a cada curs canvia tot: "Acostume a estudiar l'espai moltes vegades durant cada curs escolar. Així que no és massa estàtic, però sí que tinc en compte l'amplitud, que permeta una circulació lliure, i l'estètica, que el faça agradable i acollidor» (E10).

Per altra banda, trobem docents que no sols mencionen l'aula de referència, sinó altres espais educatius, i expliquen com són i com els distribueixen:

El pati, el hall, la resta d'aules, menjador, aula multiús, gimnàs... Són espais tant oberts com tancats, dotats de materials, o diàfans, en funció d'allò que vulguem realitzar. Els distribuïm en funció del que vulguem fer. Utilitze un o un altre, tot i que a causa del tipus d'organització escolar que tenim la major part del temps estem a l'aula assignada. (E22)

Semblantment, un altre informant afirma: «Utilitzem tota l'escola [...]. Es distribueixen per ambients d'aprenentatge de lliure circulació» (E14). Altres informants donen molta importància al pati com a espai a l'aire lliure: «Per a nosaltres és molt important. Tenim un pati molt gran, molt natural, molt divers, i això ens serveix per a treballar molts continguts i moltes coses» (E24).

Pel que fa a la gestió del temps, el defineixen com un contínuum: «El temps és un contínuum, és una successió de vivències dins l'aula i el vivim d'una manera molt natural, sense presses. Hi ha temps d'acollida, temps de joc i activitat, d'higiene, d'alimentació, de descans, de converses grupals» (E10).

Per altra banda, els docents mencionen que tenen un horari distribuït per moments educatius, però que en el dia a dia no el solen respectar, perquè s'adapten a les necessitats $i$ als interessos dels infants:

Arribem de matí $i$ el que fem és mirar quines propostes farem al llarg del dia i anem adequant-nos a l'hora d'eixida i entrada del pati per a continuar fent la proposta que no acabem. Si la proposta no l'acabem continuem al dia següent. (E6)

Com explica aquest docent, cal reorganitzar el temps segons els grups d'infants i les seues necessitats: "He hagut de reestructurar el temps durant aquest curs depenent del seu ritme i també depenent del dia a dia. Treballe en funció de com estan els infants» (E27). 
El període d'acollida és un punt important per als infants, per a les famílies i per als mestres. A poc a poc s'està aconseguint que les famílies entren dins de l'aula per tal de gestionar aquesta figura d'aferrament entre l'infant i la família. A continuació, un informant explica com és el període d'acollida i destaca que les famílies són molt importants en aquest procés:

Un punt important en el període d'acollida són les famílies, perquè sense elles no pot haver-hi una bona acollida per als infants. Entren a poc a poc, i les famílies [...] s'hi estan tot el temps que necessiten. El primer dia n'entren cinc i s'hi estan tot el dia [...]. Perquè les necessitats ahí no són sols de l'infant, sinó també són de la família. A vegades és la família la que necessita estar més estona amb l'infant. Al dia següent n'entren cinc més de 9 a $10 \mathrm{~h}$, i a les $10 \mathrm{~h}$ entren els cinc del dia anterior. L'adaptació considerem que és durant tot el curs o potser dos cursos. Donar la individualitat i el respecte del ritme a cada u això és important, $\mathrm{i}$ sobretot no llevar als xiquets dels braços de les famílies. (E24)

Els recursos humans són els elements necessaris per al desenvolupament de l'infant, així com el paper del docent en la vida de l'infant a l'escola. La família també es considera un recurs personal essencial dins l'escola. Segons els informants, podem trobar famílies que s'involucren en l'escola d'una manera o d'una altra: «Les famílies hi participen de forma directa i indirecta, ja que aquestes estan convidades a vindre a classe per a participar en la vida diària de l'aula a través d'un taller de famílies» (E2).

Aquest informant valora molt positivament la relació que té amb elles:

Molt activa, i molt continuada. Tenim molta comunicació sobretot en el dia a dia i també en les festes, en reunions. Quan ells tenen preocupacions i venen a l'aula a veure què podem fer. Jo pense que tindre les famílies al costat és tindre molt de guanyat, perquè va tot molt rodat. (E22)

Una cosa que cal tenir en compte és saber-les escoltar: "És molt important escoltar-los per veure quines carències tenen, quines necessitats tenen» (E18). Ara bé, també podem trobar altres realitats:

Molt trista, no volen participar i així ho verbalitzen. Et diuen que no els emboliques molt, et verbalitzen que si els porten a l'escola és perquè ho necessiten i que ells no poden entrar dins l'escola. Per a mi el vincle amb la família és fonamental i crec que es pot fer un treball molt bonic família-escola, i més amb criatures $\tan$ xicotetes. (E13)

Potser per manca de temps, per la disponibilitat o per algun altre motiu a les famílies els costa, com bé fa saber un altre informant: «El treball des de casa molt bé, però quan els dius que vinguen a I'aula a fer coses ja els costa més» (E26).

De materials se'n poden trobar molts i de molt variats, amb diferents característiques i diferents maneres d'utilitzar-los: «Fem ús de materials per a assolir els objectius establerts, materials que donen moltes opcions d'ús, i no una única resposta ni forma de fer» (E1). Respecte al tipus de materials, els diferencien així: «Estructurats i no estructurats. Tots aquells necessaris per al desenvolupament de les propostes i la construcció personal. [...] Són materials per crear lliurement des de la imaginació i la creativitat, oberts, que permeten diferents possibilitats d'ús» (E10).

Pel que han explicat els docents en referència al material, estan fent un canvi, llevant tot el material de plàstic i introduint material de fusta i natural. "El material és un mix del que teníem i de les noves adquisicions. Intentem que siga tot de fusta i que estiga a l'abast d'ells» (E19) i «preferiblement de fusta o materials naturals, evitant materials perillosos i intentant reutilitzar objectes» (E1). En infantil és cabdal tenir materials que puguen manipular i amb els quals puguen experimentar: 
En infantil és molt important el material manipulatiu per a la vista, per al tacte. Intentem l'equip d'infantil anar generant material, però de vegades el material és el que tenim. També elaborem materials i intentem llevar el plàstic i posar cosetes de fusta. Intentem utilitzar material natural que elaborem nosaltres, que siga visual, que es preste a la manipulació, materials que siguen autocorrectius, que ells puguen utilitzarlos autònomament. (E27)

$\mathrm{Hi}$ ha docents que prefereixen tindre materials que els infants no han vist abans, que siguen nous, perquè així els poden donar un altre significat, a més de desenvolupar la seua creativitat:

Intente també tenir materials que ells no hagen vist mai perquè crec que se'ls pot traure més profit. Són materials de rebuig que estan nous i es poden aprofitar per a fer moltes coses. Materials que a ells no els resulten familiars, perquè així poden anar més enllà en la creativitat. (E22)

Per altra banda, els informants mencionen els pocs recursos econòmics que tenen a les escoles, la qual cosa suposa un inconvenient a l'hora de comprar materials educatius: "Intente que no siguen d'un alt cost perquè les escoles no solen tindre recursos» (E13).

L'avaluació és un altre element del procés d'ensenyança-aprenentatge. La majoria dels docents apunten al fet que l'avaluació en educació infantil es fa mitjançant l'observació directa, a més de registrant tot allò que s'observa:

La millor forma d'avaluació que tenim els docents és l'observació directa i sistemàtica dels xiquets i les xiquetes. [...] És important documentar els moments més significatius del nostre alumnat. [...] S'aconsegueix captar la seua evolució en un determinat aspecte del seu procés. (E2)

Com bé diuen els entrevistats, a l'hora d'avaluar tenen en compte els objectius del currículum, però no per a avaluar amb ítems sinó per a fer un informe qualitatiu i personal de cada infant:

Es tenen en compte els objectius generals establerts pel currículum, però sobre ells no es fa una avaluació quantitativa sinó que s'avalua de forma qualitativa fent una descripció sobre aspectes com ara relacions, aprenentatges, interessos, quan es necessita acompanyament, ritmes. (E1)

D'altra banda, els docents també s'han d'autoavaluar: "L'avaluació no sols és allò que fan els xiquets. Crec que és molt important també allò que hem preparat les mestres o els materials que hem proposat» (E22). Els entrevistats esmenten tots els instruments que utilitzen per a avaluar, com ara «un anecdotari o registre d'observacions diàries, fotografies i alguna graella d'avaluació individual» (E2), o «les transcripcions de converses, que m'ajuden a recordar allò que un xiquet és capaç de fer, [...] em permeten observar i escoltar amb atenció allò que està passant» (E10).

\subsection{Els rols dels implicats en el procés d'ensenyança-aprenentatge}

La tercera i última qüestió que s'aborda en aquest article és el rol dels implicats en el procés d'ensenyança-aprenentatge, que respon al paper de l'infant i al paper del docent. Els docents entrevistats defineixen l'infant com un «ésser únic i diferent, protagonista del seu propi procés d'aprenentatge i descoberta, qui camina cap a l'autonomia personal a partir dels seus propis esforços i intents, acompanyat sempre per una figura d'adult» (E2).

L'entenen també com un «ésser en continu desenvolupament amb unes capacitats, potencialitats i interessos, [...] actiu i capaç de construir coneixements i significats a partir de la interacció amb els adults» (E5), i com una «criatura en plena evolució que necessita un acompanyament amb presència, 
serenitat i enteniment, perquè necessita desenvolupar al cent per cent tot el seu potencial que té. Llavors, si la tasca com a docents no la fem bé, el que és la criatura pura l'esbiaixem» (E13).

A la idea de l'infant se li atribueixen uns valors determinats, i així ho manifesta un informant:

La imatge de l'infant comprèn una sèrie de valors que inclouen la diversitat, la incertesa, la subjectivitat, el diàleg, la democràcia, l'experimentació i l'exploració. Per tant, amb aquesta visió de l'infant com a persona activa en els seus propis processos, caldrà entendre l'aprenentatge com una activitat cooperativa i comunicacional, mitjançant la qual els infants construeixen coneixements i n'extrauen el significat del món.

El paper que tenen avui en dia els docents ha canviat molt $i$ intenten identificar-se com a acompanyant: «Intente ser més una acompanyant o guia, observant els infants per a ajudar-los en el seu creixement i adquisició d'aprenentatges» (E1). Un altre docent especifica com és el seu paper a l'aula: «El d'acompanyar els diferents processos d'aprenentatges que es donen a l'aula, estar present, preparar l'espai i els materials adaptats a les característiques i necessitats observades» (E3). Així mateix, els docents expliquen la funció que tenen ells a l'aula: "Preparar les activitats, guiar, acompanyar en els aprenentatges, observar els infants, escoltar, documentar, interpretar la informació, avaluar i també aprendre juntament amb els alumnes» (E5), o «Estudie i investigue, [...] participe activament en les reunions d'equips docents. Em documente sobre la manera com aprenen els xiquets i les xiquetes. M'entreviste regularment amb les famílies» (E10).

D'altra banda, de vegades el paper del docent pot ser contradictori: «Jo em considere acompanyant, observadora de les necessitats i facilitadora de recursos. Però la realitat em fa ser, moltes vegades, dirigent, organitzadora» (E11). Hi ha docents que expliquen com els agradaria ser, en el sentit que estan en un procés de canvi: "M'agradaria ser un acompanyant de l'aprenentatge, però és molt difícil, ja que porta molta motxilla d'anys enrere» (E12), o "Un model de mestra amable: deixar-los fer, que s'expressen, promoure i motivar-los per a fer-los pensar; oferir-los confiança perquè ells se puguen obrir, dialogar amb ells» (E18).

\section{Conclusions i discussió}

Al llarg d'aquest article s'ha pogut veure com són les pràctiques dels docents en l'aula d'educació infantil i quines pedagogies alternatives porten a terme. L'objectiu d'aquesta investigació consistia a explorar les pràctiques educatives de trenta-cinc docents d'educació infantil que desenvolupen pedagogies alternatives en les seues aules, i això ha permès donar veu als docents i conèixer quines són aquestes pràctiques, com les apliquen i perquè treballen així.

Dels resultats es desprèn que la majoria dels docents sí que tenen un pedagog o pedagoga de referència, però també n'hi ha d'altres que s'inspiren en diverses pedagogies (Ferri, 2019). També s'ha vist quines són les pedagogies alternatives que els docents posen en pràctica a l'aula, entre les quals les que més s'han nomenat han sigut l'enfocament de Reggio Emilia, Montessori, Waldorf i l'educació viva. Els resultats d'aquest estudi evidencien com els mestres entrevistats fan una interpretació eclèctica dels diferents referents pedagògics, de vegades fins i tot antagònics entre ells, per a justificar la seva pràctica i la seva organització de l'aula. Açò evidència l'esforç que fan les docents per a identificar i «posar nom» als corrents educatius o propostes metodològiques que apliquen a la seua aula. S'ha pogut comprovar que no totes les mestres presenten un model tancat i clarament definit del que entenen per pedagogies alternatives, sinó que cada una porta a terme una proposta atenent les necessitats i realitats del seu alumnat i del context 
en el qual treballen. Aquest fet demostra que no hi ha receptes o instruccions clarament definides en l'acte didàctic, i que la reflexió docent continua sent un element clau cap a la millora del procés d'ensenyançaaprenentatge. Igualment, açò posa de manifest la riquesa i la singularitat dels diferents contextos educatius. Podem dir que, en la majoria dels casos, les seues propostes pedagògiques es recolzen en una insatisfacció davant les pràctiques d'aula que portaven a terme anteriorment i se sustenten en una reflexió constant cap a un canvi de mirada o posicionament envers l'infant.

A l'hora d'adaptar els continguts curriculars, els docents ho fan tenint en compte les necessitats i els interessos dels infants (Alabart, 2017; Cardoso i García-Torralba, 2018; García, 2017; Malaguzzi, 2011; Silvente, 2017), però al mateix temps seguint una metodologia en què la peça fonamental sempre és l'aprenentatge mitjançant el joc. El joc és l'element més important de l'aprenentatge (Cardoso i GarcíaTorralba, 2018; Díaz, 2019) i així ho han expressat els entrevistats. Els docents mencionen que els agrupaments i les estructures d'aprenentatge pretenen fomentar la interacció amb iguals, amb infants de diferents edats i amb els que tenen els mateixos interessos (Trilla i Puig, 2003).

Per als docents l'aula és el principal espai on es produeix el procés d'ensenyança- aprenentatge (Zarrias, 2019), però també esmenten el pati i l'hort com a espais exteriors, a banda d'altres espais com les altres aules i els passadissos. Pel que fa a la distribució de les aules, s'ha pogut comprovar que aquestes estan en canvi continu i distribuïdes per ambients o per zones d'aprenentatge (Carbonell, 2019; Trueba, 2015), en funció dels interessos i les necessitats que tenen els infants (Zarrias, 2019). Respecte a la gestió del temps, els agradaria disposar de més temps per no trencar els aprenentatges que s'estan fent; d'aquesta manera el conceben com un contínuum. La distribució del temps és flexible i depèn de cada cas (Albert, 2019; Estremeda, 2018; Trueba, 2015). Tots tenen un horari, però com bé sabem en infantil es regix per moments educatius. Pel que fa als recursos humans, veuen que les famílies sí que s'involucren en l'educació dels seus fills participant en les activitats, però de vegades els agradaria que hi participaren més (Cardoso i GarcíaTorralba, 2018). Cal fer esment de la participació d'alguns docents en projectes en què hi ha vinculats agents comunitaris (García, 2017).

En els recursos materials s'ha pogut detectar com els docents estan llevant tots els materials de plàstic $\mathrm{i}$ estan començant a introduir elements naturals i de fusta (Moreno, 2013), però evidentment aquest canvi va molt a poc a poc per l'alt cost econòmic que tenen els materials de fusta, el qual les escoles no poden assumir. Per aquesta raó els materials que més busquen són materials no estructurats i materials de rebuig, perquè pretenen promoure la creativitat, l’experimentació i la manipulació (Trueba, 2015).

L'avaluació és un altre element important de tot aquest procés, perquè s'avaluen els diferents components que intervenen en el procés d'ensenyança- aprenentatge. S'avalua mitjançant l'observació directa, en què els docents prenen nota de tot allò que veuen rellevant en l'evolució de cada infant i que després comuniquen a les famílies a través d'un informe redactat i personalitzat (Bersaluce, 2009; Davoli, 2016; Díaz, 2019). Els instruments que utilitzen són graelles, anecdotaris, diaris, fotografies, etc.

A l'infant el defineixen com a protagonista dels seus propis aprenentatges i el veuen com un ésser en continu desenvolupament, amb unes capacitats innates i que a poc a poc va descobrint els seus interessos i les seues necessitats (Díaz, 2019; García, 2017). Pel que fa al paper que té el docent, aquest va molt més enllà de ser un acompanyant del procés de l'aprenentatge de l'infant: també prepara les activitats i els ambients, escolta i observa en tot moment el que fa l'infant, documenta i interpreta tot allò que veu, avalua i s'autoavalua i fa reunions amb les famílies (Riba, 2019; Zarrias, 2019). Els docents caminen cap al canvi per tal de millorar la seua pràctica docent. 


\subsection{Limitacions i línies futures}

Pel que fa a les limitacions de la recerca, cal mencionar que per a recollir les dades solament s'han utilitzat les entrevistes als docents. Resultaria d'interès fer entrevistes a altres agents implicats en el procés d'ensenyança-aprenentatge, com són les famílies o els agents comunitaris. A causa de l'etapa evolutiva de l'alumnat d'infantil podria incorporar-se la seua veu amb altre tipus d'activitats més visuals. També resultaria interessant recollir informació de les pràctiques d'aula a partir de l'observació de les situacions a classe o a través de l'anàlisi documental dels materials generats en la pràctica educativa.

Aquesta investigació ens ha obert nous horitzons per ampliar la mirada cap a futures investigacions basades en com es poden aplicar les pedagogies alternatives en altres etapes educatives com ara l'educació primària o l'educació secundària.

\section{Referències}

Alabart, M. A. (2017). La educación viva. En R. Jové (ed.), La escuela más feliz (p. 269-278). La Esfera de los Libros.

Albert, I. (2019). Educando en el respeto: Hacia una pedagogia viva y activa. Grupo Editorial Círculo Rojo.

Altimir, D. (2017). Com escoltar els infants? Temes d'infància, 53. Rosa Sensat (Associació de mestres).

Altimir, D. (2019). Mirades: Més enllà de les pedagogies alternatives. Revista Escoles sense armaris, 397. https://www.rosasensat.org/revista/escoles-sense-armaris-num-397/mirades-mes-enlla-de-lespedagogies-alternatives

Bersaluce, R. (2009). Las escuelas reggianas como modelo de calidad en la etapa de educación infatil. Aula Abierta, 37(2), 123-130.

Bisquerra, R. (coord.) (2004). Metodología de la investigación educativa. La Muralla.

Brailovsky, D. (2018). Lo nuevo y lo tradicional en educación: Una oposición engañosa. Revista Senderos Pedagógicos, 9(9), 161-176.

CAIEV (s. d.). Centre d'assessorament i investigació d'escola viva [web]. https://caiev.com

Carbonell, J. (2019). Pedagogías del siglo XXI: Alternativas para la innovación educativa. Octaedro.

Cardoso, C., i García-Torralba, M. (2018). Enséñale a pensar diferente. Toromítico, Editorial Almuzara.

Davoli, M. (2016). Documentar la vida dels infants a l'escola: Xarxa territorial d'educació Infantil a Catalunya. Temes d'infància, 59. Rosa Sensat (Associació de mestres).

Díaz, M. P. (2019). Panorama actual de las pedagogías alternativas en España. Papeles Salamantinos de Educación, 23, 247-281. https://doi.org/10.36576/summa.108394

Estremeda, L. (2018). Ser niños acompañados: Crianza y escuela. Universo de las Letras. 
Ferri, G. (2019). Educar de 0 a 6 anys: Com s'està transformant l'escola? Revista Infància, 220. https://www.rosasensat.org/revista/infancia-220/compartir-sempre-es-aprendre

García, A. (2017). Otra educación ya es possible: Introducción a las pedagogías alternativas. Litera.

Jové, R. (ed.) (2017). La escuela más feliz. La Esfera de los Libros.

L'Ecuyer, C. (2014). Educar en el asombro. Plataforma Editorial.

Malaguzzi, L. (2011). La educación infantil en Reggio Emilia. Octaedro.

Miles, M., i Huberman, A. (1994). Qualitative data analysis. Sage Publications.

Moreno, P. L. (2013). Rosa Sensat, la cultura material de l'escola i el material d'ensenyament. Temps d'Educació, 44, 77-99.

https://www.raco.cat/index.php/TempsEducacio/article/view/268250/355820

Muñoz, B. (2017). El método Montessori. En R. Jové (ed.), La escuela más feliz (p. 337-350). La Esfera de los Libros.

Riba, G. (2019). L'escola en construcció: Un camí en i per a la transformació. Grupo Editorial Círculo Rojo.

Sales, A., Moliner, O., i Traver, J. A. (2019). Estrategias de investigación-acción participativa para la transformación. En B. Ballesteros (ed.), Investigación social desde la práctica educativa (p. 225266). UNED.

Sandín, M. P. (2003). Investigación cualitativa en educación: Fundamentos y Tradiciones. McGrawhill.

Silvente, J. (2017). La educación en Reggio Emilia. En R. Jové (ed.), La escuela más feliz (p. 351-361). La Esfera de los Libros.

Stern, A. (2017). Jugar. Litera.

Trilla, J., i Puig, J. M. (2003). El aula como espacio educativo. Cuadernos de Pedagogía, 325, 52-55.

Trueba, B. (2015). Espacios en armonía: Propuestas de actuación en ambientes para la infancia. Octaedro.

Wild, R. (2011). Educar para ser: Vivencias de una escuela activa. Herder.

Zarrias, E. (2019). Un cambio de mirada: Los inicios de una escuela pública activa. Ediciones Disset. 